\title{
Competences as Human Assets: A Perspective
}

\author{
H.H.D.N.P.Opatha \\ Department of Human Resource Management \\ University of Sri Jayewardenepura \\ Opatha@sjp.ac.lk
}

\begin{abstract}
This paper seeks to give a perspective with regard to competences as human assets. It is argued that an individual who wants to be successful on work life and non-work life as well needs to possess seven competences, i.e., technical competence, human relation competence, conceptual competence, intelligence, personality, individual character, and personal management competences which have to be learnt by acquiring knowledge, attitudes and skills from the two sources, i.e., heredity and environment which consists of education, training and experience. Motivation of the individual moderates the relationship between the seven competences and success. Finally a personal approach for building competences is presented.
\end{abstract}

Key words: Attitude, Competence, Human Asset, Knowledge, Motivation, Skill

\section{Introduction}

It is theoretically and empirically evident that success of any organisation heavily depends on quality of its human resources. Quality of human resources heavily depends on competences they possess. At individual level, success of the work life and non-work life heavily depends on the extent of so-called competences the person possesses. The term 'competence' is a frequently used one at present. What is a competence? Is it knowledge or skill? What are knowledge and skills? Then what about attitudes? What are abilities and capabilities? Are they convergent or divergent? How does knowledge differ from skills? What types of competences do we need to achieve success on the job/work life and non-work life? How can we build those competences to be successful? These are some of the questions for which answers are blur and not succinct. Different answers may be possible and in fact existing literature of Management does not reveal concise descriptions. This paper is a systematic attempt to give a perspective that gives answers for the above questions to a certain succinct extent or at least to a plausible extent. In fact an attempt is made to give a more simple, practical and plausible explanation with regard to competences rather than a more scholastic explanation. Consequently the paper seeks to provide a general comprehension of competence with a comparison between competence and frequently used related terms. Ostensibly, the approach of the paper is more reflective and descriptive. Also the paper gives a new label human asset for 'competence'. 


\section{Toward A Definition of Competence}

The meaning of competence (also termed as competency) is not concrete as the concept is abstract. Word itself is ambiguous as it has several meanings. Also there are several terms such as capability, ability, attitudes, knowledge, and skill which are often used in practice synonymously or interchangeably. From the focus of this paper it is about a person's competence. A universally accepted definition is unavailable. The New Oxford Thesaurus of English (2000) defines competence as capability and that someone described as competent has the necessary skill or knowledge to perform a particular task or fulfil a particular role. According to this definition competence resembles skill or knowledge. Competence is the ability to do something well or effectively and its opposite word is incompetence (Collins Birmingham University English Language Dictionary, 1987). The same Dictionary defines that someone who is 'competent' has the ability, knowledge, and skill to do something in an efficient and effective way. The same defines 'ability' as quality or level of skill in doing a particular thing; 'efficient' as doing a job well and successfully, without wasting time and energy; and 'effective' as working well and producing the results that were intended. Accordingly competence is an ability possessed by a person to do something successfully. Successful doing denotes achieving intended results (goals) without wastage of resources such as time, energy and so on. The English Business Dictionary (1986) defines competent as able to do something or efficient. The Oxford Paperback Dictionary (1979) defines competent as having the ability or authority to do what is required. The same defines authority as the power or right to give orders and make others obey; a person or group with such power; and a person with specialized knowledge, a book etc. that can supply reliable information. In this context the term 'competent' is associated with the ability rather than the authority. The same defines 'ability' as the quality that makes an action or process possible, the capacity or power to do something. The Dictionary of Personnel Management (1990) defines competence as being efficient and 'competent' as able to do something. This Dictionary definition is identical to the definition given by the English Business Dictionary. Viewing from the above dictionary definitions, competence is about an individual ability to do something successfully. Ability is the degree to which you are capable of performing (Dunham, 1984).

Dessler (2005) defines competences as demonstrable characteristics of a person that enable performance of a job. Dessler's definition is more relevant to work setting and it includes characteristics of a person which are able to be shown or proved enabling him/her to perform a certain job. Basic characteristics that can be linked to enhanced performance by individuals or teams are competences (Mathis and Jackson, 2000). This definition indicates competences as fundamental features possessed by individuals or teams contributing to improve performance.

The term 'capability' is also used in the context of competence. The New Oxford Thesaurus of English (2000) defines capable as competent. The Collins Birmingham University English Language Dictionary (1987) defines 'capability' as the ability or the qualities that are necessary to something. Also the same treats 'capability' as a synonym to 'competence'. 'Capable' is defined as able or clever enough to do something by the 
English Business Dictionary (1986). The Oxford Paperback Dictionary (1979) defines 'capable' as competent; and having a certain ability or capacity. Thus, the term 'capability' has been used as a synonymous term for 'competence' and it is treated so for the purpose of this paper too.

Much of the literature does not give a clear distinction between knowledge and skill. What is knowledge? Is it skill or is it different from skill? Exhibit 1 gives some Dictionary definitions with regard to these two terms.

Exhibit: 1 Dictionary Definitions of Knowledge and Skill

\begin{tabular}{|c|c|c|}
\hline Source & Knowledge & Skill \\
\hline $\begin{array}{l}\text { The New Oxford Thesaurus } \\
\text { of English (2000) }\end{array}$ & $\begin{array}{l}\text { 1. Understanding } \\
\text { 2. Learning } \\
\text { 3. Awareness } \\
\text { 4. Familiarity with } \\
\text { 5. Information }\end{array}$ & $\begin{array}{l}\text { 1. Expertise } \\
\text { 2. Accomplishment }\end{array}$ \\
\hline $\begin{array}{l}\text { The Collins Birmingham } \\
\text { University English } \\
\text { Language Dictionary (1987) }\end{array}$ & $\begin{array}{l}\text { Information and } \\
\text { understanding about a } \\
\text { subject which a person has } \\
\text { in his or her mind or which } \\
\text { is shared by all human } \\
\text { beings }\end{array}$ & $\begin{array}{l}\text { 1. The knowledge and } \\
\text { ability that enables you to } \\
\text { do something such as a job, } \\
\text { game, or sport very well } \\
\text { 2. A type of work or an art } \\
\text { or craft which requires } \\
\text { special training and } \\
\text { knowledge }\end{array}$ \\
\hline $\begin{array}{l}\text { English Business Dictionary } \\
\text { (1986) }\end{array}$ & What is known & $\begin{array}{l}\text { Ability to do something } \\
\text { because you have been } \\
\text { trained }\end{array}$ \\
\hline $\begin{array}{l}\text { The Oxford Paperback } \\
\text { Dictionary (1979) }\end{array}$ & $\begin{array}{l}\text { 1. Knowing } \\
\text { 2. All that a person } \\
\text { knows } \\
\text { 3. All that is known, an } \\
\text { organized body of } \\
\text { information }\end{array}$ & $\begin{array}{l}\text { Ability to do something } \\
\text { well }\end{array}$ \\
\hline
\end{tabular}

Viewing from the above dictionary definitions, knowledge is what you know or an organized body of information while skill is your ability of performing something. Knowledge is the degree to which you possess information (facts, concepts, principles, theories etc.) and understanding about a certain thing (for example, employee interviews) and skill is the degree to which you are capable of performing that certain thing (for example, employee interviews). With knowledge of something you know what it means, for what it is, how it works, and where it works. With skill of something you will have the ability to do it well. Knowledge is to understand something while skill is to activate on something. Knowledge is mainly for comprehension of a certain thing while skill is mainly for performance of that certain thing.

A nominal definition assigned to the term 'competence' in this paper is as follows: 
"An individual's capability or ability of performing a certain task or a role or a job successfully".

\section{Seven Human Assets}

An individual needs a set of competencies in order to be excellent on the job as well as on the life in general. These competencies are labelled as Human Assets (HA). An asset is something that is useful or helps an individual or an organisation to be successful. Human assets which help an individual to be successful on any job or in his or her life are considered as seven categories which are given below.

1. Technical Competence: This is the ability to use tools, techniques and methods to perform a task or an activity. It involves your ability to develop or prepare appropriate policies, procedures, rules, and budgets in a specialized field. It is one's capability about the relevant field (that may be accounting, engineering, production, human resource management, marketing etc). For instance, If you are a human resource manager you must have the capability of performing functions such as job design, job analysis, human resource planning, recruitment, selection, hiring, induction, performance evaluation, training and development, rewards management, discipline management, management of employee movements, career planning and development, grievance handling, and management of labour relations. You must possess sufficient technical competence to accomplish the job for which you are responsible. You must be able to perform the mechanics of your job.

2. Human Relation Competence: This is the ability of understanding and dealing with people without creating disorders, conflicts and confusions. It involves your ability to work with people well. It is the employee's ability to work effectively as a team member and to build cooperative effort in the unit, department or organisation. If you are a manager, you must possess abilities in communicating, motivating and leading your subordinates. In performing your duties, you will definitely have to interact with another person or a few people or many people. You are required to interact with them without making them dissatisfied. You must have the ability to make the other person happy or at least prevent him or her from becoming dissatisfied due to your interaction.

3. Conceptual Competence: This is the ability to understand the organization as a total entity. It includes your ability to comprehend all activities and interests of the organization where you are working. It includes comprehending interdependency and interrelatedness of various parts of the organization, and environmental forces and their impact on the business. Also it is your capability of defining phenomena, imagining, analyzing, synthesizing, theorizing, planning and organizing.

4. Intelligence/Mental Reasoning Competence: This is the mental ability of general reasoning. It is your ability to reason mentally and solve problems. Reasoning refers to a systematic process of arriving at a particular conclusion by 
thinking carefully about all information that is given or available. It can be divided into specific mental abilities such as inductive reasoning, deductive reasoning, non-verbal reasoning, verbal reasoning, numerical reasoning, analytical reasoning, logical diagrams reasoning, symbolic reasoning, and abstract reasoning. Refer to Opatha (2009) for a detail treatment of mental reasoning competence.

5. Personality: This is about values, preferences, likes, and dislikes of a person. It includes your talk, your physical appearance, your walk, and other unique features. It is your ability of adjusting your thinking and behaviour to relevant environment/occasion/job appropriately. It focuses on a set of personality traits which have more potential to lead to successes, namely locus of control (the degree to which you believe in that your decisions and actions determine your destiny); authoritarianism (the degree to which you believe in that there should be a clearly defined structure of authority and status); dogmatism (the degree to which you are closed-minded with tightly held beliefs); Machiavellianism (the degree to which you focus on obtaining and using power to further your own ends, regardless of the impact on others); type A/B trait (the degree to which you choose to work aggressively under pressure with an impatient and competitive approach to others) (adapting from Dunham, 1984); self-monitoring of behaviour (the degree to which you can observe and control the images and perceptions that others form about you) and extroversion (to degree to which you are very active, lively, assertive and social). It has been observed that internal locus of control, less dogmatism, less authoritarianism, less Machiavellianism, type A-, high selfmonitoring and extroversion personality trait inclinations are positively associated with managerial excellence.

6. Individual Character: This is the aggregate of all of the relatively persistent moral qualities person has that combines to form his/her real nature. That is the degree to which a person has virtues and vices. It is your ability to build and enhance virtues and minimize or eradicate vices. Virtues are about thinking and doing what are right and avoiding what are wrong or good qualities that a religion or society teaches one to respect (The Collins Birmingham University English Language Dictionary); and they are about moral excellence, goodness or good qualities (the Oxford Paperback Dictionary). Virtues are universally accepted principles and they do not differ from religion to religion, culture to culture, one nationality to another, one race to another, and one group to another group of the same nationality like values which do so. As virtues do not get different in terms of nationality, religion, race, cast, sex, and other classifications in the society, they are absolutes but not relatives like values. Values are ideals or standards upon which actions or behaviours are based and they are not universally acceptable (some values may be universally acceptable). There are values appreciated by one group of people but not appreciated (or discredited) by another group of people (i.e., respecting adults, worshiping human beings, playing crickets, doing rock music, etc). Some virtues are responsibility, honesty, patience, tolerance, respect, humility, determination, courage, persistence, initiative, caring etc. Virtues are the 
qualities to be nurtured within a person until they are upheld as a matter of habit. Opatha (2007, p. 5) writes: "Vices are negative qualities which need to be totally eradicated or alleviated within a person. In fact, character is to what extend a person possesses vices. Ideally the extent to which vices are possessed by a particular person should be zero or minimum to have the highest level of good character. They include jealousy, greed, anger, stinginess, doubt, deception, corruption, retaliation etc. Vices are the mal-qualities to be removed from a person until they become totally eradicated." For a detailed analysis about the term 'individual character', please refer to Opatha (2007).

7. Personal Management Competences which are:

(1) Ethical Thinking Competence: this is your ability of thinking ethically before making a decision. Do you have the ability to take a decision that is ethically correct, specially when you face a complex ethical decision-making or an ethical dilemma? You should be able to do an ethic test that has seven focuses namely utilitarianism, deontological perspective, character of the person, disclosure, reversibility, happiness and the most virtuous person-in-belief.

(2) Positive Thinking: perceiving the life positively, perceiving the future optimistically and having a positive self-concept (your evaluation about yourself, linked with self-esteem).

(3) Continuous Learning: you must have a passion for continuous learning. Also you should have the ability of learning continuously. Do you have a strong interest in learning continuously and do you like it very much? Do you read as a habit?

(4) Balancing Life and Work: you must be able to have a trade off between life matters and official matters. It is generally agreed that when a person is happy in his/her personal life, he/she is more efficient and effective at work. Do you maintain a balance between your work and non-work things that get you excitedfamily, hobbies, friends, whatever true passions you have? Do non-work matters disturb your work matters or otherwise? Then there is no balance.

(5) Time Management: you must have the ability of managing your workload efficiently within the available time so that your goals are achieved. What wastes your time? A good understanding of what wastes your time needs to be developed within you and also you should take actions or follow some strategies to handle your wasters.

(6) Career Management: you must have the ability of planning and developing your career. A successful professional develops a career plan and then takes actions to accomplish his/her plan. Obtaining specific career information, developing career goals and the path to those goals, and undertaking personal improvement actions towards the achievement of the career plan are main steps in career management.

(7) Stress Management: you must have the ability of coping with pressures you feel in your life. Successful management of stress will help you to be healthy and to be efficient and effective on your work in sustainable manner. 
Among the seven human assets, individual character can be perceived as the foundation for all other assets. Character will work as the basis for other assets as virtues will contribute to achieve building of other human assets. Possession of right character will lead to one to acquire, build, maintain and improve all types of competencies required to be successful on a job or profession. It is more likely that a person with a high degree of all the seven competencies will have an outstanding and illustrious career. Competence of a person is defined as the aggregate of all of the above seven groups or types of abilities he/she possesses enabling him/her to achieve success on the job being performed and on his/her life as well. Competence of a person consists of seven human assets as specified above. Following Figure includes the above human assets.

\section{Figure: 1 Seven Human Assets}

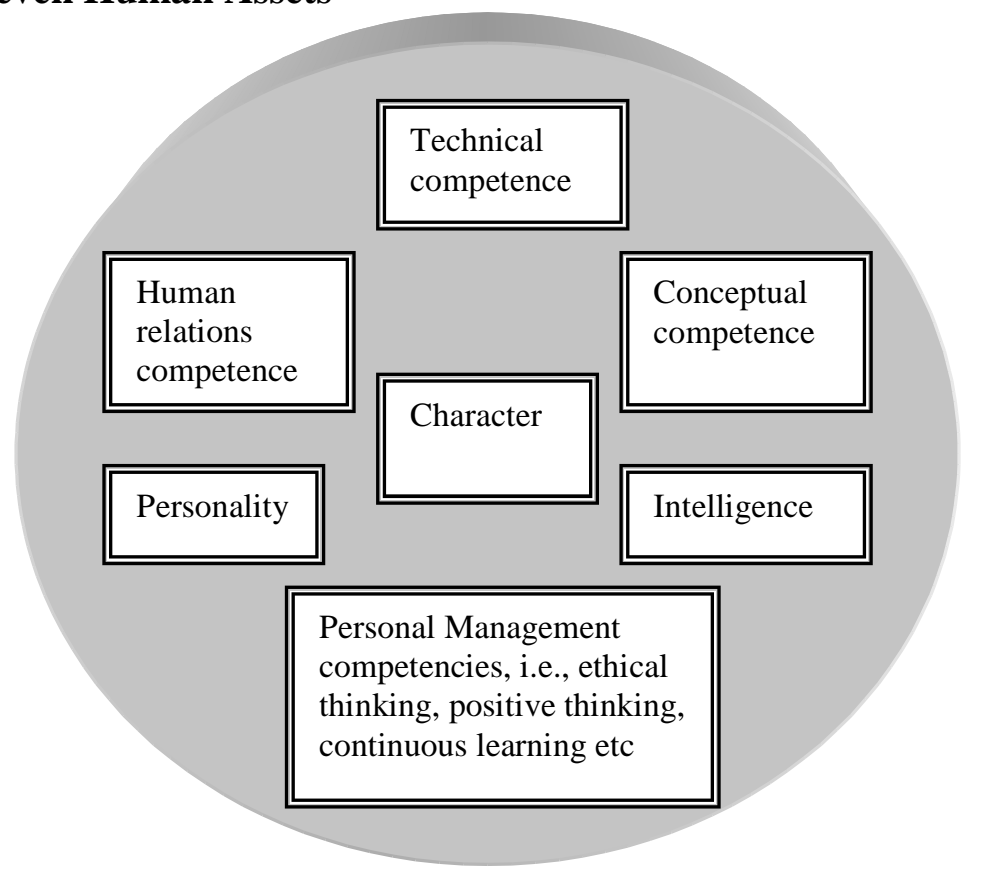

\section{Building Competences}

How to build the competencies? How are they built? In order to build the competencies one has to acquire knowledge, skills and attitudes with regard to those competencies. The acquisition of knowledge, attitudes and skills that result in a relatively permanent change in behaviour is referred to as Learning (adapted from Hodgetts, 1985). An attempt was made to define and differentiate between knowledge and skills under a previous section of the paper. What is an attitude? An attitude is the beliefs, feelings, and behavioural tendencies held by a person about an object or person (Dunham, 1984). Dunham (1984) explains that an attitude is composed of three components, i.e., cognitive (beliefs), affective (feelings) and behavioural (intention to behave). An appropriate attitude is essential to believe in the thing/object/person being considered, then to feel it positively and then, to tend to behave positively toward it. 
It is argued that a person has to learn the seven competencies by acquiring knowledge, attitudes and skills about those competencies. For instance, let us consider one competence namely technical competence. If I want to build this competence within you (to develop that ability) I will have to give information (concepts, definitions, theories, methods, procedures, rules etc) to you; and I will have to describe and explain to you so that you will understand it. What I do is in fact dissemination of knowledge. Thus, one has to acquire knowledge about the technical competence in order to build that competence within him/her. Apart from that, I will have to develop a good attitude about the technical competence within you so that you will believe in it (this competence is important to me, this is useful for my success, this will lead to others' success also), feel it positively (appreciate it, give a high weight to it) and then tend to behave appropriately to it (I will learn it; I will get that ability). In addition, I will have to allow you to acquire skill about the technical competence. You will have to do actually what you have learnt in order to get the ability. For all other types of competencies, you will have to get the right knowledge, develop the right attitude and then activate actually in the right way. Consequently it is possible for you to possess the competencies. Thus, knowledge is for getting information, knowing and understanding. Attitude is for believing, feeling positively and tending to behave positively. Skill is for doing actually.

\section{Sources of Learning}

Basically there are two sources of learning, i.e., genetics or heredity and environment. Heredity is the process by which features and characteristics are passed on from parents to their children before the children are born (the Collins Birmingham University English Language Dictionary, 1987). It is possible that special qualities and abilities are passed on from one generation to another by means of genes. You may have acquired knowledge and skills, to a certain extent, with regard to one or two or several or all of the seven human assets/competencies owing to heredity. Hence you may possess inherent or natural abilities (talents) to do something well. Generally you are not born with specific attitudes (Dunham, 1984). One may argue that there is no need of learning in case of heredity as the relevant (inherent) abilities have already been possessed by the person. And therefore heredity cannot be treated as a source of learning. However, from the perspective taken for this paper it is argued that one may be able to acquire knowledge and skills (not attitudes) about one or two or several or all of the seven human assets/competences owing to heredity and therefore heredity is a source of learning (acquiring knowledge and skills).

Second source of learning is environment that has several sub sources which include education, training and experience. Education may be formal education (systems of teaching in schools, colleges and universities), non-formal education (following a programme of courses from institutes and other organisations of learning) and informal education (knowledge, attitudes and skills about competences learned from media; reading papers, magazines, journals, books etc; role models, superiors, peers, subordinates, customers, and other people; and association of friends and so on). Training includes a process of learning the skills that are needed by you to perform a particular job. Education is more general, less job oriented, relatively long-term and results of learning are not immediately usable while training is more specific, job oriented, 
relatively short-term and results of learning are immediately usable. Experience means knowledge or attitude or skill you have gained due to your working on the job for a long time. Under experience you learn through trail and error method mainly.

\section{Moderators}

It is likely that a person who possesses the above mentioned seven assets/competencies at high level is going to be successful on the job as well as on the life. It is theorised that there is a positive relationship between the seven competencies and success of the person on the job and the life. The higher you possess the competencies the higher your success will be. However, this positive relationship will only be true when the person has motivation (degree of willingness to exert effort to perform something successfully). In other words, only the person who possesses the seven competencies and has motivation too will be successful. Thus, motivation will be a moderator. In fact employee performance is a function of his/her ability (competence) and motivation. Motivation is a person's drive to take an action because he or she wants to do so (Werther, Davis, Schwind, Das and Miner, 1985). They (p.305) view: "If people are pushed, they are merely reacting to pressure and acting because they feel that they have to. However, if they are motivated, they make the positive choice to do something because they see the act as meaningful to them. Therefore, motivation can be simply defined as goal-oriented behaviour." There may be several other moderators such as working conditions, resource availability, etc. Figure 2 depicts competencies and related variables and their relationships.

\section{An Approach for Building Competences}

A personal approach is presented to build competencies. First you should do an evaluation with regard to your performance. A popular method known as 360 degree programme can be utilised for the purpose. The method involves use of several evaluators (at least four) and combination of all evaluations done by each evaluator. The objective of this evaluation is to determine your position or state (your degree of success) with the intention of improving it further. Two types of evaluation are needed: one for performance evaluation on your job and the other for performance evaluation on your life. Who should be evaluators? You can be an evaluator. Your boss/superior, peer, subordinate, outsider (an expert in evaluation), customer, immediate superior's superior etc. can be evaluators. Use of several evaluators will minimise disadvantages of each source and maximise advantages of each source and will result in a more comprehensive evaluation done from different perspectives. For the evaluation purpose, techniques such as BOS (Behavioural Observation Scales) or BARS (Behavioural Anchored Rating Scales) could be applied. Refer to Opatha (2009) for a detailed treatment of the BOS and the BARS. It is essential to identify Critical Observable Behaviours (COBs) which are found from highly successful people who demonstrate in performing each of the above mentioned seven competences. COBs are specific actions or activities which you can observe, perform and practice for continuous improvement. In fact use of BOS or BARS will be appropriate as they focus on COBs.

Second you should do a Gap Analysis (GA) in order to identify your weaknesses and/or behaviours for improvement. Assume your evaluation has five standards (i.e., very poor, 
poor, satisfactory, good, and excellent or very low, low, average, high and very high or almost never, rarely, sometimes, often and almost always). Your ratings as very poor and poor are your serious weaknesses and your ratings as satisfactory and good are areas for improvement. You will never develop if you do not address to your negative gap effectively.

Third you should do learning with regard to identified weaknesses and/or behaviours for improvement. You should acquire knowledge, attitudes and skills with regard to COBs which are missing from you. You will have to engage in informal education and nonformal education. Also an appropriate training will have to be secured. Observation is a good method of informal learning. You can learn the COBs by observation of successful people. It is possible to imitate their productive behaviours. Also you can learn by observing unsuccessful people. It is possible to see their unproductive behaviours/failures and resultant consequences.

Fourth you should do a review regarding your progress of building the COBs under the relevant competencies. This involves internal (self) and external search for information about your improvements. Post evaluation has to be performed and then you can compare your current ratings with your earlier ratings in order to determine whether there are improvements or not. You will get a good feedback that will have to be used for further improvement.

\section{Figure: 2 Competences and Related Variables}

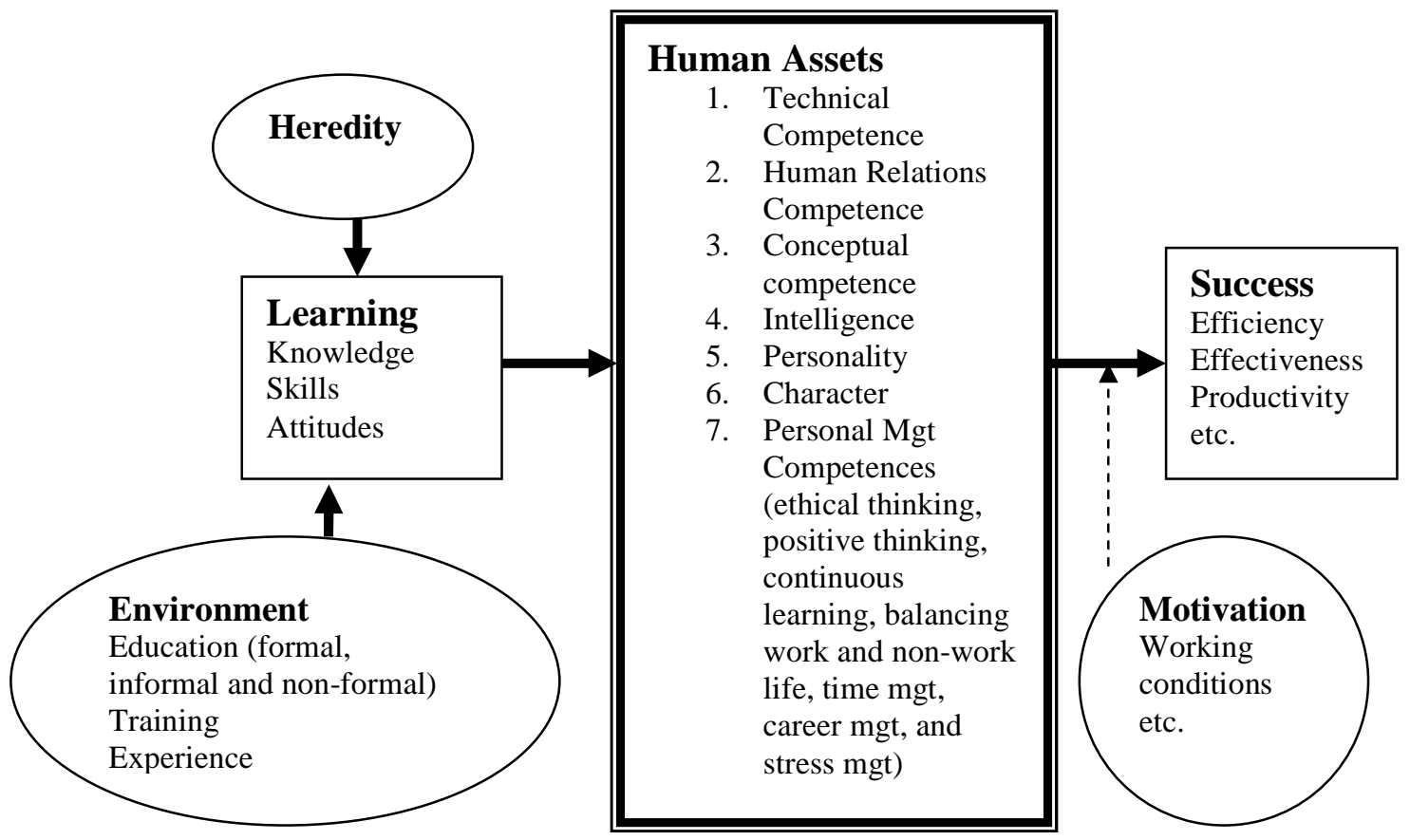




\section{Conclusion}

An individual's capability or ability of performing a certain task or a role or a job successfully has been defined as a competence. Competencies labelled as human assets include seven main types, i.e., technical competence, human relations competence, conceptual competence, intelligence, personality, character and personal management competences. These competencies are required to achieve successes on the job and also on non-work life. They are secured through learning which is the relatively permanent change in behaviour by acquiring knowledge, attitudes and skills which are secured from environment that is composed on education (formal education, non-formal education and informal education), training and experience. Heredity may provide one or some of the competencies to one to a certain extent since his/her birth. Possession of the competences does not guarantee success on work life and non-work life as well. Motivation is viewed as a main moderating variable for success meaning that a person who has the seven competences at a high degree will not be able to achieve successes unless he/she has the required motivation. A practical approach consisting of four steps, i.e., evaluation of performance, gap analysis, learning COBs, and review of progress, is proposed. Let me ask three questions from you before conclusion.

Do you want to be the best person in a certain field of Sri Lanka compared with your peers or even with non-peers/all? Can you be the best? If you think that you are not in a position of becoming the best in the field (due to some reasons which may be uncontrollable), then

Do you want to be one of the best persons in a certain field of Sri Lanka? Can you be one of the best? If you think that you are not in a position of becoming one of the best in the field (due to some reasons which may be uncontrollable), then

Do you want to be an excellent person/ a person of success in a certain field of Sri Lanka? Can you be excellent or successful?

In order to be the best or one of the best or excellent, you must possess the seven competences to a high extent. Also it is essential to maintain your excellence for a prolong period of time, if possible, until your retirement. Perfect excellence is to be an objective that can be sought but it will never be reached. You will have to improve continuously owing to creativity, innovation and changes which occur in the world in which you are living.

\section{References \\ Collins Birmingham University International Language Database (Cobuild) English Language Dictionary (1987), London: Collins.}

Dessler, G. (2005), Human Resource Management, $10^{\text {th }}$ edi, New Jersey: Prentice-Hall. Dunham, R.D. (1984), Organizational Behavior, Homewood, Illinois: Richard D. Irwin. English Business Dictionary (1986), Middlesex: Peter Collin Publishing Ltd. Hodgetts, R.M. (1985), Management, Orlando: Academic Press.

Ivanovic, A. (1990), Dictionary of Personnel Management, Middlesex: Peter Collin Publishing Ltd.

Mathis, R.L. and Jackson, J.H. (2000), Human Resource Management, $9^{\text {th }}$ edi, New York: South-Western College Publishing. 
Opatha, H.H.D.N.P. (2007), Individual Character: A Perspective, Sri Lankan Journal of Human Resource Management, Vol.1, No.1, pp. 1-13., Sri Lanka: Department of Human Resource Management, University of Sri Jayewardenepura.

Opatha, H.H.D.N.P. (2009), Human Resource Management, Sri Lanka: Author Publication.

The Oxford Paperback Dictionary (1979), Oxford: Oxford University Press.

The Oxford Thesaurus of English (2000), Oxford: Oxford University Press.

Werther, W.B., Davis, K., Schwind, H.F., Das, H., and Miner, F.C. (1985), Canadian Personnel Management and Human Resources, Toronto: McGraw-Hill. 